\title{
The introduction of navigation in liver surgery in Brazil
}

\section{A introdução da hepatonavegação no Brasil}

\author{
Mauro Monteiro Correia, TCBC-RJ1; José Paulo de Jesus, TCBC-RJ1; Raul Feitosa²; Dário Augusto Oliveira ${ }^{2}$
}

\section{A B S T R A C T}

\begin{abstract}
The authors thoroughly report the development, the technical aspects and the performance of the first navigated liver resections, by laparotomy and laparoscopy, in Brazil, done at the National Cancer Institute, Ministry of Health, using a surgical navigator.
\end{abstract}

Key words: Diagnostic techniques and procedures. Imaging, three-dimensional. Image processing, computer-assisted. Liver. Hepatectomy.

\section{INTRODUCTION}

Sictor ince 2007, The Abdomino-Pelvic Surgery Division of the Cancer Hospital I, José Alencar Gomes da Silva National Cancer Institute Ministry of Health, (HC I-INCA/MS), the National Council for Scientific and Technological Development (CNPq), the Foundation for State Research of Rio de Janeiro (FAPERJ), the Professor José de Souza Herdy Grande Rio University (UNIGRANRIO) and the Department of Electrical Engineering of the Pontifical Catholic University (PUC) collaborate, in Rio de Janeiro, in the development of a computational tool dominated "3D-Liver"1,2. This is a software platform capable of processing medical images, perform three-dimensional evaluation, the calculation of volumes and the implementation of semi-automatic and automatic methods of liver recognition. It has since helped the planning of operations in the liver performed in INCA. The prototype can be seen on the video, whose link is <http://www.Ivc.ele.puc-rio.br/projects/Liver3D/ 3dliver.avis.

During the planning phase of hepatectomy, the three-dimensional reconstruction with preoperative analysis of imaging exams allows the physician to better understand the relationship between tumors and vessels. At laparotomy the surgeon can use the vision and touch, but during laparoscopy there is great touch loss and vision is two-dimensional. During percutaneous procedures, the only location feature are the spatial coordinates provided by the scanner. The aiding diagnostic tools, such as ultrasound and real-time intraoperative navigation, have the potential to increase the security and the radicalism of hepatectomies and ablations for cancer ${ }^{3-8}$.
This article aims to report the technical aspects and the performance of the first navigated liver resections, by laparotomy and laparoscopy, in Brazil

\section{TECHNIQUE AND PROCEDURES}

Surgical navigation consists in matching the volume created on the computer with the actual liver volume (record) to "navigate" over and through the liver, using an instrument with retro-reflexive spheres (passive navigation) tracked by an infrared camera (Figure 1). Navigation is routine in neurosurgery and has long ceased to be

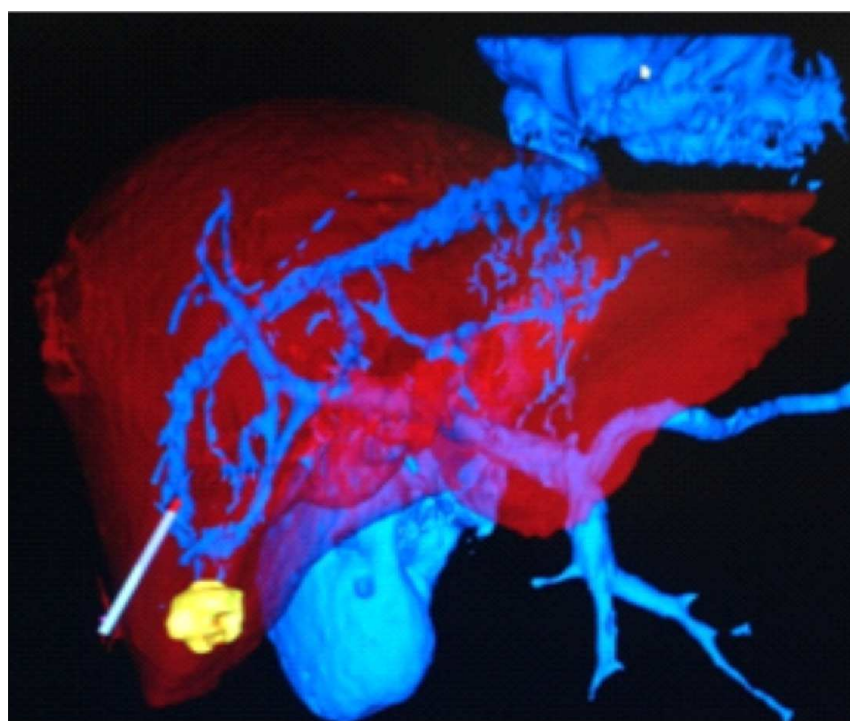

Figure 1 - Liver, selected vessels, tumor and the virtual instrument correlated with the tracked instrument manipulated by the surgeon.

1. José Alencar Gomes da Silva National Cancer Institute, Ministry of Health, Rio de Janeiro, Brazil; 2. Pontifical Catholic University of Rio de Janeiro. 
considered an investigational procedure. It can be used in hepatic resections by laparotomy, laparoscopy, robotic surgery and ablation procedures. The drawing in Figure 2 shows the preoperative steps of image processing (importing and preparation).

The necessary steps for hepatic navigation are: Preoperative: a) Importing the images to the software tool; b) preparation of the study with editing and rendering; $c$ ) preparation of the equipment in the room (set up); Intraoperative: a) registration and b) navigation. As we did not have integration with a navigation system, in September 2012 we seeked a national firm specialized in navigation, creator of EXIMIUS ${ }^{\circledR}$, a system registered with the National Health Surveillance Agency - ANVISA. It consists of an infrared camera connected to a computational tool for importing images in the DICOM format, capable of threedimensional reconstruction and navigation of traceable instruments (Figure 3). The system designers had no experience in image processing and liver operations, so we started our collaboration for the development of hepatic navigation in Brazil. It took several meetings, studies and adjustments before proceeding to the clinical phase.

In the first case selected, the patient was properly informed and signed a Informed Consent form, her tomography being used for the preoperative process steps. She was a lady of 66 years of age with chronic $C$ hepatitis,

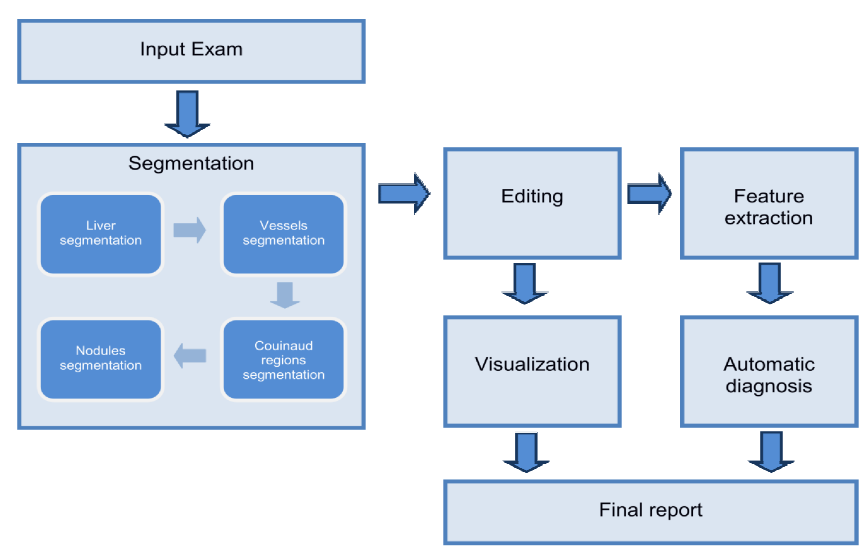

Figure 2 - $\quad$ Preoperative steps of image processing (importing and preparation).
CHILD A, without portal hypertension. She had undergone a left extended hepatectomy seven years before, due to a single hepatocellular carcinoma (HCC). During follow-up, there was the emergence of a second lesion, with characteristics consistent with a HCC in the fifth segment (Figure 4). The operation took place in October 2012 at the HC I-INCA/MS, Rio de Janeiro, and consisted of laparotomy and sub-segmental resection under the guidance of intraoperative ultrasound and navigation. There was no blood transfusion. It was possible to locate the vessels of interest and to set safe limits for resection (Figure 5), the wound margins were studied by frozen section examination. There were no intraoperative complications. We used intraoperative ultrasonography as the gold standard and the correlation was accurate. The patient recovered well and was discharged on the sixth postoperative day (PO).

For the second selected case, we used the navigation to perform laparoscopic hepatectomy (Figure 6). The patient signed an informed consent. She was a 45year-old woman who had undergone emergency colostomy and subsequent left colectomy, followed by node ablation in segment $V$ three months before. However, the patient

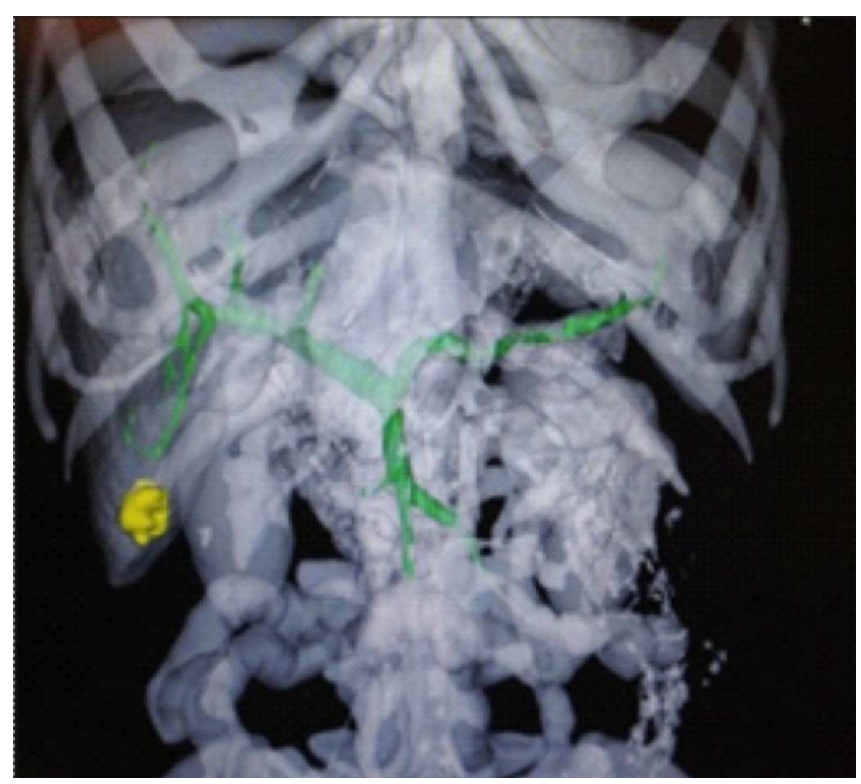

Figure 4 - Image of liver with tumor in segment $V$.

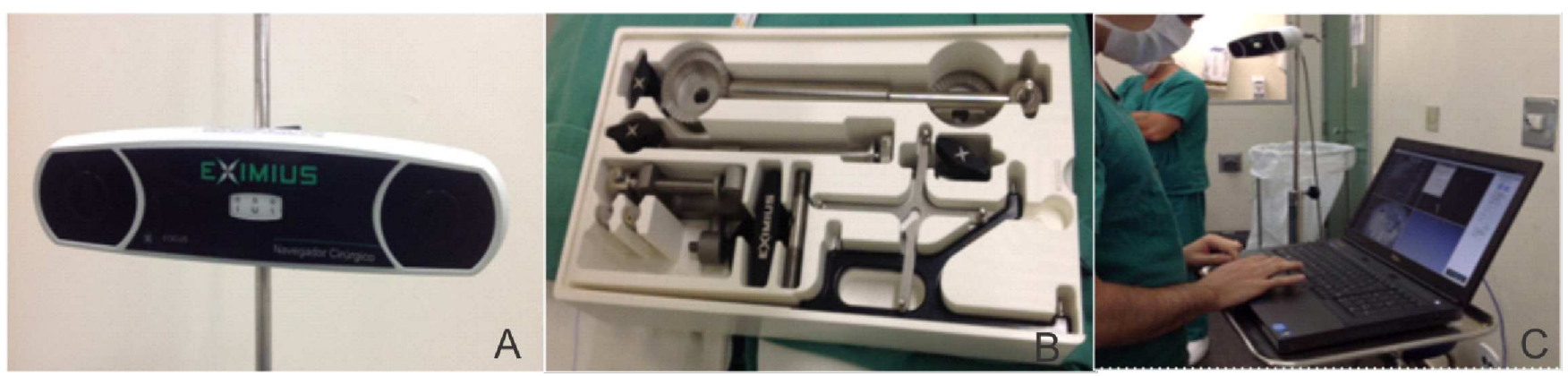

Figure 3 - Components of the Eximius system: A) camera; B) instruments; and C) computer with navigation platform. 


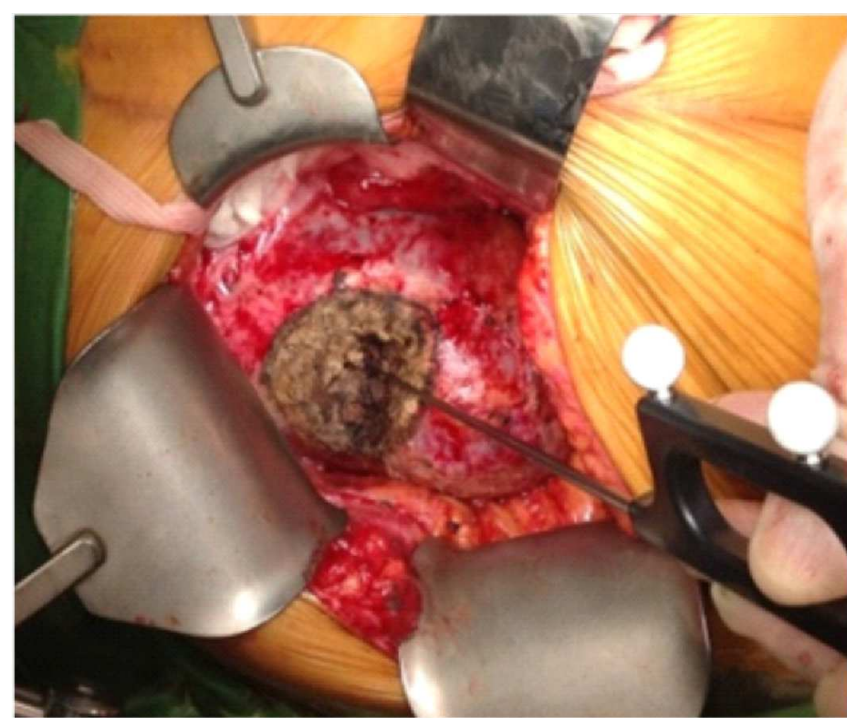

Figure 5 - Verification of vessels and limits after resection.

remained with a lesion in the segment II/III, not subject to ablation. Her images were recorded, reconstructed and the procedure was planned. The laparoscopic hepatectomy went smoothly in October 2012 with guidance, instruction, and direct participation of physicians from Barretos Cancer Hospital. There were many adhesions from the prior procedures, but after lysis, it was possible to inspect the entire cavity and the liver. For navigation, we coupled the claw with retro-reflexive balls with the power clamp, which can be recognized on the screen with images of the liver in 3D. We were then able to locate the intrahepatic vessels before the fragmentation of the liver tissue, anticipating their location. The operation consisted of left lateral sectionectomy, with navigation without blood transfusion. The patient recovered well and was discharged on the third postoperative day.

\section{DISCUSSION}

With hepatic navigation one can perform safer operations, with fewer accidents, less risk of bleeding, potentially better radicality and chances of cure at a lower cost. Commercially available equipments for hepatic navigation have variable cost, between US\$150,000 and US\$ 600,000, much higher than the domestic similar we used. Probably, hepatic navigation will be more useful in laparoscopic hepatectomy; in reoperations, where the vascular anatomy suffers strains and displacements; and in extended resections. In some centers, hepatic navigation has the potential to provide: 1) more radicality, precisely defining the required limits or by aiding in the location of lesions that have become sub-millimetrical or disappeared from imaging after chemotherapy; 2 ) realtime monitoring of the needle location and the ablation area, without interference from the steam, as in intraoperative ultrasonography; 3 ) greater security with fewer accidents and less bleeding; 4) gain in time in laparoscopic operations; 5) reducing related costs by enabling more judicious use of automatic vascular staplers; and 6) acceleration of the learning curve in laparoscopic liver surgery. Several obstacles exist for surgical navigation to be sufficiently precise and reliable, especially the need for the navigation monitor to follow the deformity of the liver caused by real time mobilization and eliminating errors resulting from liver movement during ventilation ${ }^{9,10}$. These initial procedures show that it is possible to use surgical navigation equipment in liver operations. To overcome these limitations of the method, we performed the measurements and records in short periods of apnea and with the liver in the anatomical position. We continue to perform hepatectomies with hepatic navigation and we expect to publish qualitative results soon.

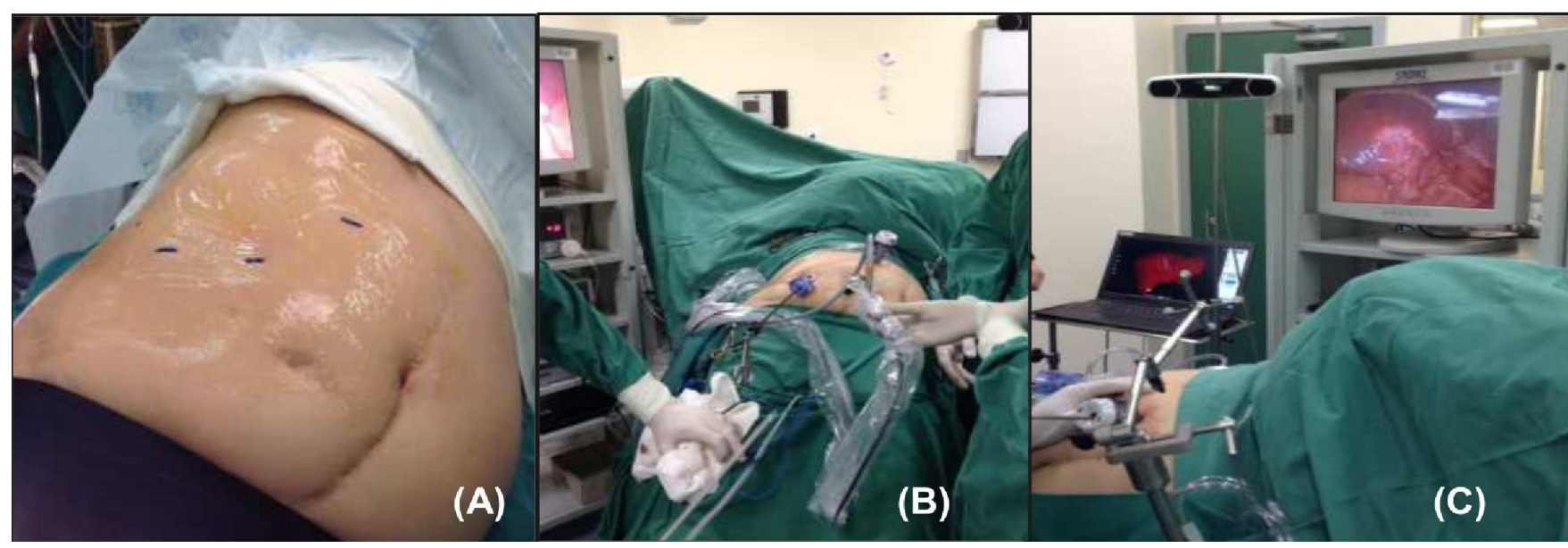

Figure 6 - Navigated laparoscopic segmentectomy of the segment V: A and B) location of the ports; C) monitoring of hepatectomy with navigator. 


\section{R E S U M O}

Os autores relatam minuciosamente o desenvolvimento, os aspectos técnicos e a realização das primeiras ressecções hepáticas navegadas, por laparotomia e por laparoscopia, no Brasil, feitas no Instituto Nacional de Câncer, Ministério da Saúde, Brasil, usando um navegador cirúrgico.

Descritores: Técnicas e procedimentos diagnósticos. Imagem tridimensional. Processamento de imagem assistida por computador. Fígado. Hepatectomia.

\section{REFERENCES}

1. Oliveira $D A B$, Feitosa RQ, Correia MM. Segmentation of liver, its vessels and lesions from $C T$ images for surgical planning. Biomed Engin online. 2011;10:30.n

2. Especialistas da PUC-Rio e do INCa desenvolvem protótipo de plataforma para auxiliar no diagnóstico do câncer de fígado e no planejamento cirúrgico. Rev Rio Pesquisa (FAPERJ). 2011;16(4):Medicina e tecnologia:15-7

3. Oliveira DAB, Feitosa RQ, Correia MM. Automatic Couinaud liver segmentation using CT images, Viplmage - Thematic Conference on Computational Vision and Medical Image Processing. 2007 Oct.

4. Correia MM, Oliveira DAB, Feitosa RQ. Building an automatic 3D liver segmentation model for surgery planning. In: Anais do XXVII Congresso Brasileiro de Cirurgia, 2007; Belo Horizonte: Colégio Brasileiro de Cirurgiões; 2007 jul 8-12.

5. Oliveira DAB, Feitosa RQ, Correia MM, Automatic couinaud liver and veins segmentation from CT Images. In: BioSignals International Conference on Bio-Inspired Systems and Signal Processing. Funchal; 2008 Jan. p. 249-52.

6. Oliveira DAB, Feitosa RQ, Correia MM, Genetic adaptation of level sets parameters for medical imaging segmentation. In: Gonzalez FA, Romero E, organizes. Biomedical image analysis and machine learnen technologies: applications and techniques. New York: Medical Information Science; 2010. p.150-65.

7. Lang H, Radtke A, Hindennach M, Schroeder T, Frühauf NR, Malagó $M$, et al. Impact of virtual tumor resection and computer-assisted risk analysis on operation planning and intraoperative strategy in major hepatic resection. 2005;140(7):629-38, discussion 638.

8. Guimarães CM, Correia MM, Baldisserotto $M$, de Queiroz Aires EP, Coelho JF. Intraoperative ultrasonography of the liver in patients with abdominal tumors: a new approach. J Ultrasound Med. 2006;23(12):1549-55.

9. Oliveira $D A B$, Feitosa $R Q$, Correia MM. Liver segmentation using level sets and genetic algorithms [conference paper]. In: Conference: VISAPP 2009. Proceedings of the 4th International Conference on Computer Vision: Theory and Applications; 2009 Feb 5-8.

10. Oliveira DAB, Feitosa RQ, Correia MM. Genetic adaptation of level sets parameters for medical imaging segmentation. In: Biomedical image analysis and machine learning technologies: applications and techniques, IGI Global, 2009. (Chapter proposal accepted)

Received 20/10/2013

Accepted for publication 20/01/2014

Conflict of interest: none.

Source of funding: APQ1 - FAPERJ; Scientific Initiation Scholarship CNPq; SISPLAN - INCA / MS.

Mailing address:

Mauro Monteiro Correia

E-mail: mmauro.monteiro@gmail.com 